Safety first
Bringing technology
to bear in the search
for tighter security
$p 238$

\title{
Scientists react to attacks with shock and fears for the future
}

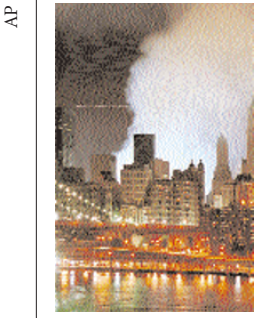

\section{Washington \& London}

The horrific events of 11 September in New York and Washington have left scientists - in common with people from all walks of life - struggling to comprehend the brutality involved, and deeply worried about the potential consequences. Although shock and grief remain the dominant emotions, scientific leaders are already asking if the political, economic and security landscape will now shift in ways that make it impossible to adopt a 'business-asusual' approach to research.

Scientists worldwide were quick to express sympathy and solidarity with American colleagues and with the victims of the attacks. Some scientific events were cancelled or curtailed as a mark of respect, and on 13 September the US National Academies posted on their website a selection of the messages received from other research organizations. These led with an expression of "deep sympathies and condolences" to the American people from Fathi Arafat, president of the Palestine Academy for Science and Technology. "I must say we were all utterly shocked and dismayed at the terrible human loss incurred and the excruciating pain that ensues," Arafat wrote. "May God ease your pain and grant you patience."

But scientific leaders must now think beyond their immediate emotional responses and consider the practical consequences of the current crisis. Today's scientific enterprise relies heavily on international collaboration, the free exchange of data, and unrestricted travel. In the current unstable geopolitical climate, it is unclear how each of these will be affected.

Given the nature of last week's attacks, concerns about the safety of air travel loom large (see overleaf). Leading scientists, and those in senior positions in government research agencies and high-tech industry, are among the world's most frequent fliers. There is currently a strong determination - particularly on the part of US researchers - to carry on as normal. "We should take whatever means in security measures to mediate this so that we shake hands, look eye-to-eye, stand shoulder-to-shoulder," says Robert Goldston, director of the Princeton Plasma Physics Laboratory in New Jersey — where a meeting to celebrate 50 years of plasma physics was postponed last week. "We should not allow this event to affect the way we do science."

Even scientists who have been touched directly by last week's tragedy echo those feelings. Jan Mous, chief scientific officer with Lion Bioscience, a biotech company in Heidelberg, Germany, says that international travel will remain central to the functioning of his industry. But for Mous, such contemplation is secondary to his concern for the family of Klaus Sprockamp, Lion Bioscience's chief finance officer, who is listed among those missing at the World Trade Center in New York. "We can only pray that a miracle has happened," says Mous.

\section{Escalating tension}

The extent to which scientists will resume their hectic travel schedules is likely to hinge on future events, however. Any suggestion that airliners remain vulnerable to hijacking by suicide bombers is bound to dent people's resolve to keep flying. Already, carriers are reducing the number of scheduled flights. And if last week's outrage leads to war between the United States and scattered terrorist groups and the states that harbour them, as seems likely, international scientific travel could be severely curtailed. "If there is a riposte, then I stop travelling immediately and completely," the research director of a leading European pharmaceutical company told Nature.

Such concerns are now foremost in the minds of the organizers of major scientific meetings. In the days immediately after the attacks, organizers of the largest pending conferences were optimistic that they could proceed as normal. But as events continued to unfold, some scientific societies began to reconsider their plans.

The American Society for Microbiology, for instance, which was expecting some 15,000 delegates to attend its 41st Interscience Conference on Antimicrobial Agents

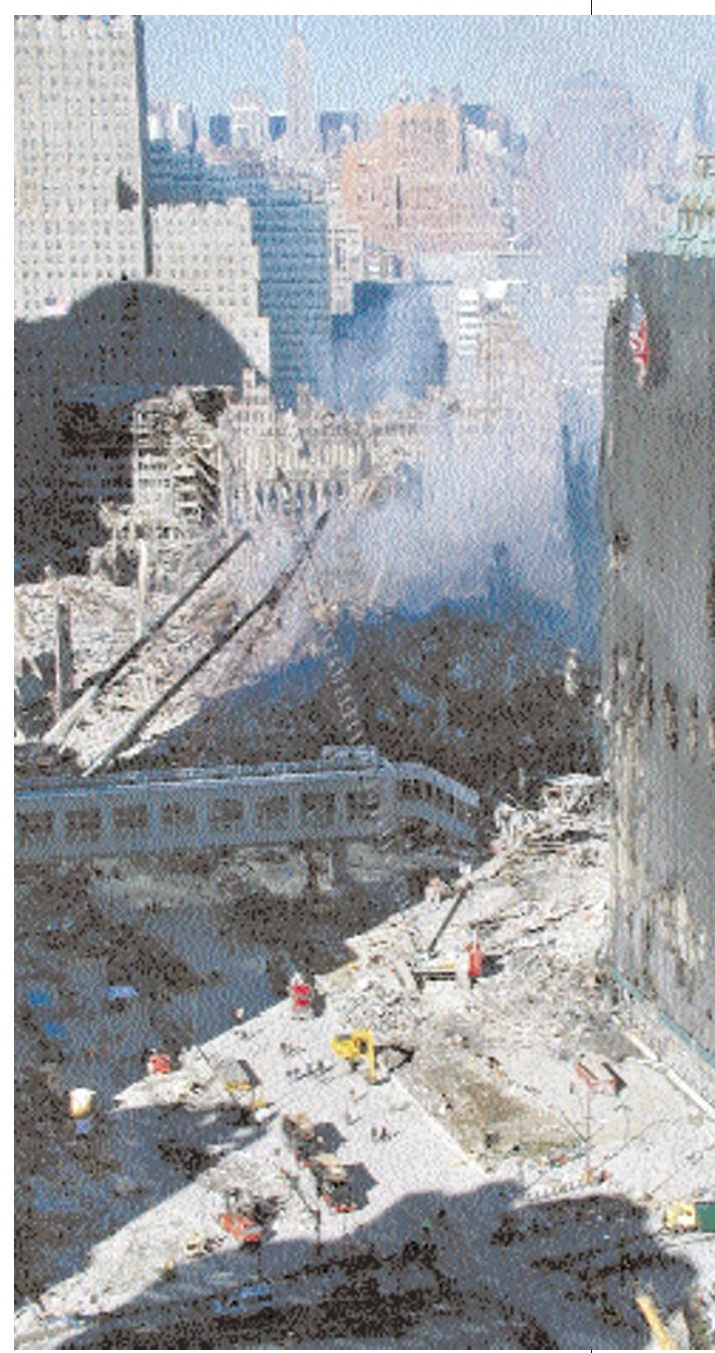

Devastation: workers remove rubble after the collapse of the World Trade Center.

and Chemotherapy in Chicago on 22-25 September, initially issued the following statement: "We believe that in response to the national tragedy that has occurred, holding this important scientific meeting is in the best interests of human health and welfare." But by 14 September, the conference's organizers had decided to postpone the meeting until December, noting that "uncertainties concerning the availability of safe, scheduled air travel force us to take this action in 


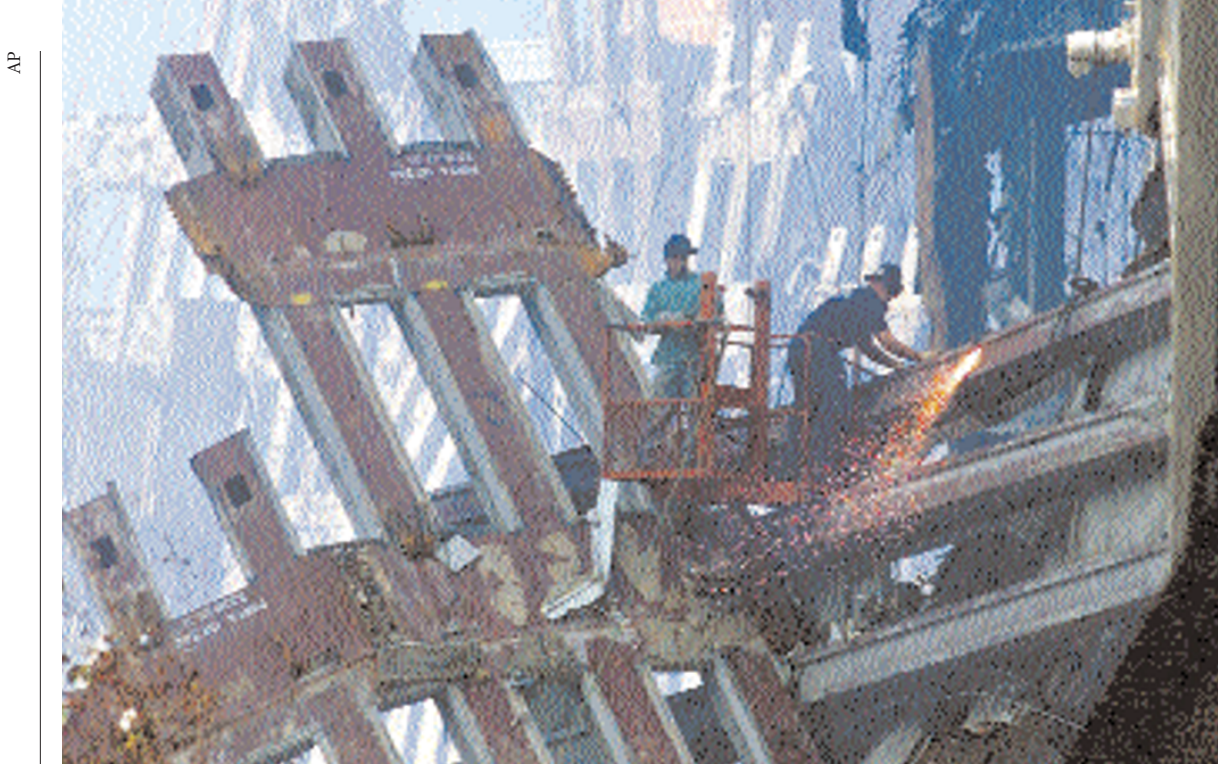

Science officials in the regional neighbours of Afghanistan — the most likely target of US military action - are acutely aware of the potential for a security clampdown to affect international scientific collaboration. "It is too early to say in what form restriction will come," says Ragunath

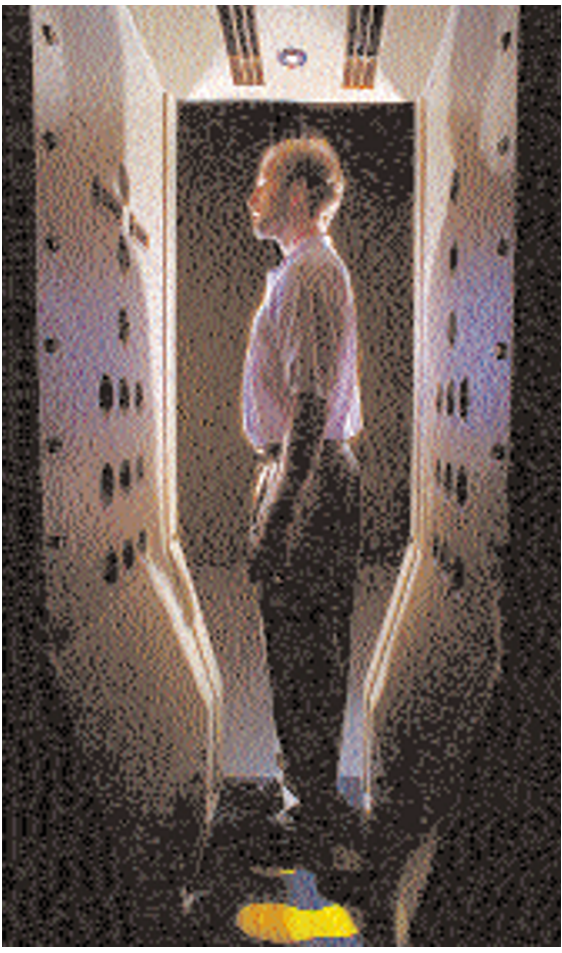

with procedures to keep cabin doors locked during flight. US officials are also discussing a major expansion to the Air Marshal programme, to put armed guards on many more scheduled flights. Discharging a firearm during pressurized flight is dangerous - but Israel's airline, El Al, equips its guards with nylon composite bullets that can disable hijackers without threatening cabin walls.
Mashelkar, secretary to India's Department of Scientific and Industrial Research. "But there is bound to be some restriction on the freedom that non-Americans currently enjoy in the United States."

More generally, the crisis could have a profound effect on the resources that are

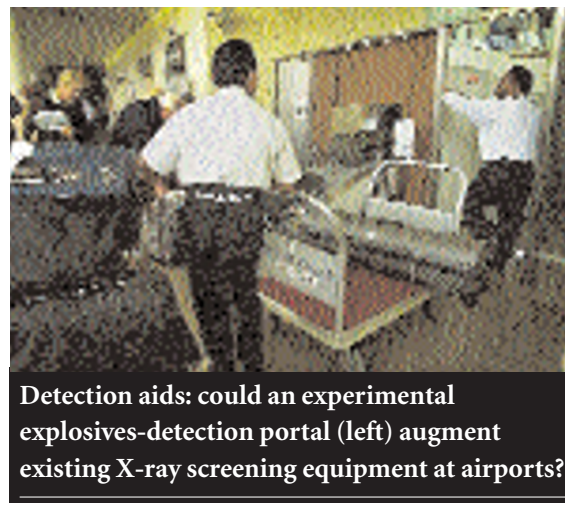

Charles also believes that auto-pilot technology could be further developed to prevent hijackers seizing control of aircraft. "We've had fully automatic landing capability for a long time." With current technology, he says, "it wouldn't take great additional effort to implement a system that would activate fully automatic flight and landing and disable all manual control inputs".

But the system could create problems if it malfunctioned, and denied control to legitimate pilots. Developing telemetry to override manual inputs and assume control from the ground in the event of hijacking would help. But that, in turn, might be vulnerable to someone hacking into the system. Such complications illustrate how, in combating terrorism, securing one area of vulnerability often creates another.

Some researchers complain that the FAA's lengthy certification process has delayed the adoption of promising security techniques. A made available for research. The US federal budget will come under pressure as money is released for the immediate relief effort, for eventual rebuilding at the sites of the attacks and to finance the expected military action. Already, the US Congress has authorized the spending of $\$ 40$ billion for rebuilding and to step up security. "The money has to come from somewhere," observes Robert Eisenstein, assistant director of the mathematical and physical sciences directorate of the National Science Foundation.

Although officials such as Eisenstein are duty-bound to consider the potential implications of the crisis for their agencies' budgets, such concerns are not foremost among the scientists who spoke to Nature over the past week. "There are thousands of widows, widowers and orphans," says Princeton University physicist William Happer, director of the Office of Energy Research in the US Department of Energy during the early 1990s. Under the circumstances, he says, most scientists will accept that fundamental research is not going to be the US government's top priority.

Reported by Alison Abbott, David Adam, Josette Chen, Rex Dalton, K. S. Jayaraman and Paul Smaglik. team at Sandia National Laboratories in Albuquerque, New Mexico, for example, developed a screening portal in 1997 that can detect explosives carried by passengers. After two years of tests at Albuquerque's airport, a New Jersey company, Barringer Technologies, bought rights to the technology, but the FAA has yet to certify it.

The FAA will now come under pressure to expedite its certification procedures. Its research priorities may also be reviewed. The administration spends around $\$ \mathbf{5 0}$ million a year on research and development, about $\$ 40$ million of it on explosives detection.

However, the events of 11 September suggest that, whatever technologies become available, they cannot provide watertight security. There is no "magic bullet", warns John Hansman, a physicist and director of the International Center for Air Transportation at the Massachusetts Institute of Technology. "Any technical solution for security will be highly vulnerable to a well-planned attack."

As the US authorities investigate the vulnerabilities that allowed last week's attacks to occur, a top priority will be providing better intelligence on terrorist activities. "Intelligence tells you what the threat scenario is," says Harris, "but intelligence on terrorism is a severe weakness of the system right now." Addressing that weakness may require vast reforms of both human spying and the use of technologies such as electronic communications interception. Additional reporting by Rex Dalton. 